\title{
MOTIONS IN JUPITER'S ATMOSPHERE
}

\author{
R. HIDE \\ Geophysical Fluid Dynamics Laboratory Meteorological Office, Bracknell, Berkshire, England
}

\begin{abstract}
Recent contributions to the dynamics of Jupiter's atmospheres were reviewed under the following headings: (a) general magnitude of winds and temperature fluctuations; (b) cloud bands and zonal velocity profile (including equatorial jet); (c) transient non-axisymmetric features (spots, and irregular markings); (d) the Great Red Spot.
\end{abstract}

\section{Some Useful References}

Banos, C. J.: 1971, Icarus 15, 58.

Banos, C. J. and Alissandrakis, C. E.: 1971, Astron. Astrophys. 15, 424.

Barcilon, A. and Gierasch, P. J.: 1970, J. Atmospheric Sci. 27, 550.

Gierasch, P. J.: 1970, Earth Terrest. Sci. 4, 171.

Gierasch, P. J.: 1973, Icarus 19, 482.

Gierasch, P. J., Ingersoll, A. P., and Williams, R. T.: 1973, Icarus 19, 473.

Golitsyn, G. S.: 1971, Atmospheric Oceanic Phys. 7, 974.

Goody, R. M.: 1969, Rev. Astron. Astrophys. 7, 303.

Hide, R.: 1969, J. Atmospheric Sci. 26, 841.

Hide, R.: 1974, Proc. Roy. Soc. London A336, 63.

Hogg, N. G.: 1973, J. Fluid Mech. 58, 517.

Hogg, N. G. : 1973, Deep Sea Res. 20, 449.

Hubbard, W. B.: 1973, Space Sci. Rev. 14, 424.

Inge, J. L.: 1973, Icarus 20, 1.

Ingersoll, A. P. and Cuzzi, J. N.: 1969, J. Atmospheric Sci. 26, 981.

Layton, R. G.: 1971, Icarus 15, 480.

Kuiper, G. P.: 1972, Sky Telesc. 43, 75.

Leovy, G. B. and Pollack, J. B.: 1973, Icarus 15, 195.

Lewis, J. S.: 1973, Space Sci. Rev. 14, 401.

Maxworthy, T.: 1973, Planetary Space Sci. 21, 623.

Newburn, R. L. and Gulkis, S.: 1973, Space Sci. Rev. 3, 179.

Reese, E. J.: 1973, Icarus 17, 57.

Starr, V. P. and Rosen, R. D.: 1972, Tellus 24, 73.

Stone, P. H.: 1973, Space Sci. Rev. 14, 444.

Streett, W. B., Ringmacher, H. I., and Veronis, G.: 1971, Icarus 14, 319.

Williams, G. P. and Robinson, J. B. : 1973, J. Atmospheric Sci. 30, 684.

\section{DISCUSSION}

Heard: Are the bands regarded as holes in an upper cloud layer through which we see a lower cloud layer?

Hide: The bands comprise belts and zones. It is generally considered that the zones, which are bright, are regions of rising motion where ammonia cirrus clouds form and that the belts, which are dark, are regions of descending motion, where ammonia cirrus does not form.

Low: Our recent Astrophys. J. paper shows a strong correlation between temperature measurements at $5 \mu$ and 'cloud' colour. The blue clouds are hot ( $T$ about $250-300 \mathrm{~K})$; the red, brown clouds are cold ( $T$ about $200 \mathrm{~K})$ and, therefore, presumably higher.

Gehrels: It seems urgent, and interesting, to use photographs of Jupiter to measure cloud motions.

Baum: Profiles of rotation period as a function of latitude are being measured and analysed by Jay 
Inge in my group at Lowell Observatory, particularly seeking short term variations. A paper by Inge concerning sampled time intervals in 1970, 1971, and 1972 will soon appear in Icarus. In the hope of detecting more detail (perhaps non-laminar) in the atmospheric flow pattern, I am attempting by image rectification to construct pseudo-time-lapse sequences as they would be seen from a synchronous satellite in an equatorial orbit around the planet; but that is a rather difficult task, it will take time to do, and it may not succeed. Our purpose, however, is to make sure that we detect all of the image information inherently available in the patrol photographs. 